\title{
COMMENTARY
}

\section{Is fibrinogen the answer to coagulopathy after massive transfusions?}

\author{
Samuel A Tisherman* \\ See related research by Grottke et al., http://ccforum.com/content/14/2/R62
}

\begin{abstract}
Coagulopathy is a major cause of morbidity and mortality in patients who have suffered severe

hemorrhage and received massive transfusions. Administration of a fibrinogen concentrate along with red blood cells can quickly restore hemostasis in a clinically relevant animal model.
\end{abstract}

Severe traumatic injury is frequently associated with hemorrhagic shock necessitating massive transfusions. Patients frequently become coagulopathic because of the combination of dilution of platelets and clotting factors, metabolic acidosis, hypothermia, and consumption of clotting factors. Although replacement of blood loss with fresh whole blood would be ideal, this is not possible in civilian situations under current blood-banking practices. Standard therapy involves the administration of packed red blood cells (PRBCs), fresh frozen plasma (FFP), platelets, and cryoprecipitate. The last of these is administered primarily to replete fibrinogen, which is commonly decreased by dilution as well as consumption. In the previous issue of Critical Care, Grottke and colleagues [1] explored the potential use of a fibrinogen concentrate instead.

Although these blood products are life-saving, they do have risks. In general, the more blood products administered, particularly PRBCs and FFP, the greater the risk for multiple organ system dysfunction and mortality [2-4]. Immunologic responses appear to play a major role.

In contrast, recent studies have suggested a beneficial effect of cryoprecipitate administration. In a military population of patients receiving massive transfusions, the ratio of fibrinogen (from all blood products) to PRBCs transfused was associated with reduced mortality [5].

*Correspondence: tishermansa@upmc.edu

Departments of Critical Care Medicine and Surgery, University of Pittsburgh, 638 Scaife Hall, 3550 Terrace Street, Pittsburgh, PA 15261, USA
Similarly, in a large database of civilians, administration of cryoprecipitate was associated with a decreased risk of multiple organ dysfunction [2].

Fibrinogen plays a critical role in hemostasis as it promotes platelet aggregation and, when activated to form fibrin, provides the substrate for red blood cells and platelets to form strong clots. In theory, administration of exogenous fibrinogen when the endogenous levels are low could bypass missing components of the clotting cascade.

Grottke and colleagues [1] have explored the use of different doses of a fibrinogen concentrate to correct the coagulopathy caused by hemodilution and to decrease bleeding in a clinically relevant animal model of trauma and hemorrhagic shock. This work builds upon the work of Fries and colleagues [6], which used a larger dose of fibrinogen. Fries and colleagues found a dose-dependent improvement in standard clotting studies and thromboelastograms (TEGs). Even with a relatively low dose, the authors found decreased bleeding and improved survival compared with controls. They also found no evidence of harm from the fibrinogen administration.

The model used in the study by Grottke and colleagues seems to be well designed to explore questions related to trauma and coagulopathy. The liver injury simulates severe trauma with active bleeding, which can be quantified. Coagulopathy is induced by hemodilution in a way that may be typical of the clinical situation of massive transfusion and fluid resuscitation without replacement of plasma, fibrinogen, or platelets. The use of the Cell Saver $^{\circledR}$ (Haemonetics, Braintree, MA, USA), which might be used clinically to salvage and re-infuse the animals' red blood cells, further simulates clinical situations. The only aspect of the model that is not clinically relevant is timing since the coagulopathy and fibrinogen concentrate administration precede hemorrhage. This limitation does not detract from the utility of the model or the importance of the findings.

The results of this study [1] suggest that replacement of fibrinogen to a certain threshold level, perhaps as low as $70 \mathrm{mg} / \mathrm{dL}$, is sufficient to provide hemostasis. Since fibrinogen needs to be activated to have an effect, it is intriguing and important to recognize that, even with 
this dilutional coagulopathy, sufficient activators seem to be present. Because of the question of activators, the authors see fibrinogen administration as adjunctive therapy to be used concomitantly with replacement of other coagulation factors.

Though not discussed much in the current paper, significant clinical experience with the fibrinogen concentrate used in this study has been reported. The product is clinically approved for use in patients with congenital fibrinogen deficiency and seems to have a good safety profile [7]. As a result, off-label use has already been reported. Fenger-Eriksen and colleagues [8] found that use of the fibrinogen concentrate improved standard clotting studies, increased fibrinogen levels, and decreased bleeding in patients with massive hemorrhage and decreased fibrinogen levels. Others have shown improved coagulation studies and decreased bleeding after cardiac [9], urologic [10], and orthopedic [11] surgery.

A secondary finding in this study is that standard clotting studies may not represent clinical hemostatic function as these normalized while the TEG remained abnormal. This finding is in agreement with others $[12,13]$ and demonstrates the complexities in objectively monitoring coagulation with severe hemorrhage, hemodilution, and massive transfusions.

So where do we go from here? Grottke and colleagues [1] give us some guidance in this regard, recommending clinical studies of optimum level, need for combination therapy, timing, and patient selection. As far as the use of fibrinogen concentrates for patients with massive hemorrhage is concerned, there seem to be sufficient preclinical and preliminary clinical data to warrant a pivotal clinical trial in patients with massive hemorrhage. The work by Grottke and colleagues [1], as well as by others, gives us good data for dosing of fibrinogen concentrate and for minimal fibrinogen levels to be achieved. Trauma patients in hemorrhagic shock would be an appropriate target population. It may be that focused restitution of fibrinogen levels with a fibrinogen concentrate is more efficient and efficacious than the use of cryoprecipitate or other blood products. Although it is unlikely that fibrinogen will be a magic bullet, it may be an excellent adjunct to blood component replacement.

\section{Abbreviations}

FFP, fresh frozen plasma; PRBC, packed red blood cell; TEG, thromboelastogram.

\section{Competing interests}

SAT is a co-holder of a patent on the "Emergency Preservation and Resuscitation Method".
Published: 14 May 2010

\section{References}

1. Grottke O, Braunschweig T, Henzler D, Coburn M, Tolba R, Rossaint R: Effects of different fibrinogen concentrations on blood loss and coagulation parameters in a pig model of coagulopathy with blunt liver injury. Crit Care 2010, 14:R62.

2. Watson GA, Sperry JL, Rosengart MR, Minei JP, Harbrecht BG, Moore EE, Cuschieri J, Maier RV, Billiar TR, Peitzman AB; Inflammation and Host Response to Injury Investigators: Fresh frozen plasma is independently associated with a higher risk of multiple organ failure and acute respiratory distress syndrome. J Trauma 2009, 67:221-227.

3. Malone DL, Dunne J, Tracy JK, Putnam AT, Scalea TM, Napolitano LM: Blood transfusion, independent of shock severity, is associated with worse outcome in trauma. J Trauma 2003, 54:898-905.

4. Sarani B, Dunkman WJ, Dean L, Sonnad S, Rohrbach Jl, Gracias VH: Transfusion of fresh frozen plasma in critically ill surgical patients is associated with an increased risk of infection. Crit Care Med 2008, 36:1114-1118.

5. Stinger HK, Spinella PC, Perkins JG, Grathwohl KW, Salinas J, Martini WZ, Hess JR, Dubick MA, Simon CD, Beekley AC, Wolf SE, Wade CE, Holcomb JB: The ratio of fibrinogen to red cells transfused affects survival in casualties receiving massive transfusions at an army combat support hospital. J Trauma 2008, 64 (2 Suppl):S79-85.

6. Fries D, Krismer A, Klingler A, Streif W, Klima G, Wenzel V, Haas T, Innerhofer P: Effect of fibrinogen on reversal of dilutional coagulopathy: a porcine model. Br J Anaesth 2005, 95:172-177.

7. Kreuz W, Meili E, Peter-Salonen K, Dobrkovsk. A, Devay J, Haertel S, Krzensk U, Egbring R: Pharmacokinetic properties of a pasteurised fibrinogen concentrate. Transfus Apher Sci 2005, 32:239-246.

8. Fenger-Eriksen C, Lindberg-Larsen M, Christensen AQ, Ingerslev J, Sorensen B: Fibrinogen concentrate substitution therapy in patients with massive haemorrhage and low plasma fibrinogen concentrations. Br J Anaesth 2008, 101:769-773.

9. Karlsson M, Ternstrom L, Hyllner M, Baghaei F, Flinck A, Skrtic S, Jeppsson A: Prophylactic fibrinogen infusion reduces bleeding after coronary artery bypass surgery. A prospective randomised pilot study. Thromb Haemost 2009, 102:137-144.

10. Fenger-Eriksen $C$, Jensen TM, Kristensen BS, Jensen KM, Tonnesen $E$, Ingerslev J, Sorensen B: Fibrinogen substitution improves whole blood clot firmness after dilution with hydroxyethyl starch in bleeding patients undergoing radical cystectomy: a randomized, placebo-controlled clinical trial. J Thromb Haemost 2009, 7:795-802.

11. Mittermayr M, Streif W, Haas T, Fries D, Velik-Salchner C, Klingler A, Oswald E, Bach C, Schnapka-Koepf M, Innerhofer P: Hemostatic changes after crystalloid or colloid fluid administration during major orthopedic surgery: the role of fibrinogen administration. Anesth Analg 2007, 105:905-917.

12. Kheirabadi BS, Crissey JM, Deguzman R, Holcomb JB: In vivo bleeding time and in vitro thrombelastography measurements are better indicators of dilutional hypothermic coagulopathy than prothrombin time. J Trauma 2007, 62:1352-1361.

13. Plotkin AJ, Wade CE, Jenkins DH, Smith KA, Noe JC, Park MS, Perkins JG, Holcomb JB: A reduction in clot formation rate and strength assessed by thrombelastography is indicative of transfusion requirements in patients with penetrating injuries. J Trauma 2008, 64:S64-S68. doi:10.1186/cc9000

Cite this article as: Tisherman SA: Is fibrinogen the answer to coagulopathy after massive transfusions? Critical Care 2010, 14:154 